\title{
RFID and Finger Print Based Dual Security System: A Robust Secured Control to Access Through Door Lock Operation
}

\author{
Md Mostafizur Rahman Komol ${ }^{1}$, Amit Kumer Podder², Md Nesar Ali ${ }^{3}$, \\ Shariar Mohammed Ansary ${ }^{1}$ \\ ${ }^{1}$ Department of Mechanical Engineering, Khulna University of Engineering and Technology, Khulna, Bangladesh \\ ${ }^{2}$ Department of Electrical and Electronic Engineering, Khulna University of Engineering and Technology, Khulna, Bangladesh \\ ${ }^{3}$ Department of Mechanical Engineering, Chittagong University of Engineering and Technology, Chittagong, Bangladesh
}

Email address:

komolmostafizur@gmail.com(Md M. R. Komol),amitpodder09@yahoo.com(A.K. Podder),nesarali455@gmail.com(Md N. Ali), shakhor.ansary@gmail.com(S. M. Ansary)

\section{To cite this article:}

Md Mostafizur Rahman Komol, Amit Kumer Podder, Md Nesar Ali, Shariar Mohammed Ansary. RFID and Finger Print Based Dual Security System: A Robust Secured Control to Access Through Door Lock Operation. American Journal of Embedded Systems and Applications. Vol. 6, No. 1, 2018, pp. 15-22. doi: 10.11648/j.ajesa.20180601.13

Received: April 26, 2018; Accepted: May 16, 2018; Published: June 15, 2018

\begin{abstract}
This paper focuses on research works of control engineering field and aims at impenetrable security system especially in case of medication, jewelry, documents \& others valuable items and mandatorily in the higher intelligence agency. Here, a developed security system with automatic sensing is introduced by the use of both Radio frequency identification (RFID) card tagging system and fingerprint sensing biometric security system to maintain the valid access of a person to a secured place. RFID reader and fingerprint sensing device work as a locker of the security and RFID tag and a validly ratified finger is considered as the key of the locker. In case of access granted entity, door bar gets opened with a servo mechanism system connected with door bar. On the contrary, no action is taken as cavalcade if the entity is considered invalid in the sensing system. These knock out the necessity for keeping track of keys or remembering a combination of password or pin. A prototype of the security system is also designed and the performance of it is tested. The satisfactory results of its performance show the validity of the system and indicate a better solution for the future security system.
\end{abstract}

Keywords: RFID, Fingerprint Sensor, Extract Minutiae, Servomotor, Strenuous Security, Automation, Door Control

\section{Introduction}

Automated assimilation and access control system has turned out to be important to defeat the security dangers looked by numerous organizations. This is a time where everything is associated with the system, where anybody can get hold of data from anyplace around the globe. Therefore, hacking of one's information is a major issue. Because of these dangers, it is imperative to have some sort of personal identification (ID) to get to one's own particular information. Different systems are introduced at various points to track the individual's movement and to confine their entrance to touchy zones in the secured area. Among standard individual ID strategies, password and ID card methods are the most observed methods. However, it is not very difficult to hack secret password now and recognizable ID cards may get lost, hence making these techniques very questionable [1].

Again, Radio frequency identification (RFID) is a remote innovation that can be utilized to evolve the entrance control system. This technology provides a revolutionary automation in various processes ranging from industrial sectors to home control [2-3]. In RFID technology, the identification of an object automatically consists of the object, location of the object or individual with a special identifier code contained with an RFID tag, which is somehow connected to or implanted in the target [4]. Because of the shaky wireless channel between RFID tag and RFID reader, security dangers against RFID system have been showing up. Numerous RFID verification conventions against the security dangers 
have been studied in [5].

The biometric security system is being used for a long time as a strong security system in different spaces. Numerous strategies are accessible in biometrics like the fingerprint, eye iris, retina, voice, confront and so forth. These distinctive strategies have certain focal points and inconveniences which must be considered in creating the biometric system, for example, system unwavering quality, value, adaptability, need of physical contact with the checking gadget and numerous different parameters [6]. Fingerprints are one of the numerous types of biometrics, used to distinguish people and check their identity. The use of fingerprint for acclimatizing has been used in law prerequisite for about a century [7-8]. The investigation of fingerprints for matching purposes requires the correlation of a few highlights of the print pattern. These incorporate patterns include total qualities of edges, and minutia focuses. It is additionally important to know the structure and properties of human skin keeping in mind the end goal to effectively utilize a portion of the imaging advancements [9].

In this paper, efforts have been made to use both RFID and biometric formula at a time to provide more safety and stronger security to access the automatic sensing of the entity and performing the verification of an accessible identity of the entity and also the automatic operation of action in case of valid access. A person must punch card with RFID tag and presses his finger on the sensor as his fingerprint must be verified to be matched instantly to access the security system. The motivation of this work is to create a more convenient way to unlock the door than the traditional key. In the key's place, an RFID tag and the fingerprint will unlock the door immediately. If somehow any trespasser manages to have RFID tagging card, he cannot access the door with his fingerprint as it will not match. Even fingerprint sensor will not be activated before the RFID card is punched. Therefore, it remains almost impossible to access for an invalid person.

\section{Related Works}

Numerous specialists have used RFID innovation in creating access control system. Reference in [10] has depicted an RFID based implanted security confirmation system with novel face acknowledgment structure. Reference in [11] depicts the outline of RFID based security and access control system for the use in lodgings inside the Punjab University premises. Reference in [12], proposes an institutionalized unique finger impression model to incorporate fingerprints which present for all finger impression layouts put away in the database while coordinating. Therefore, this two innovations i.e. RFID and fingerprints are used to outline the proposed security system.

\section{Design of the System}

The proposed security system is designed with both RFID and fingerprint sensor as an entrance permitting key. Only RFID reader part of RFID unit and the fingerprint pressing part of fingerprint unit is kept open before door as a locking system and both the RFID tag and valid fingerprint is the key to permit one to access the door. The external photographic view of the system is shown in the following Figure 1.

The internal circuit design includes RFID reader unit, fingerprint sensor, servo motor, Arduino UNO, power supply, and a breadboard. All these components are connected and the power supply is provided through jumper wires. Arduino is powered by $5 \mathrm{~V}$ supply and sensors and servo motors are provided with requisite power externally. The internal circuit diagram of the system is shown in following Figure 2.

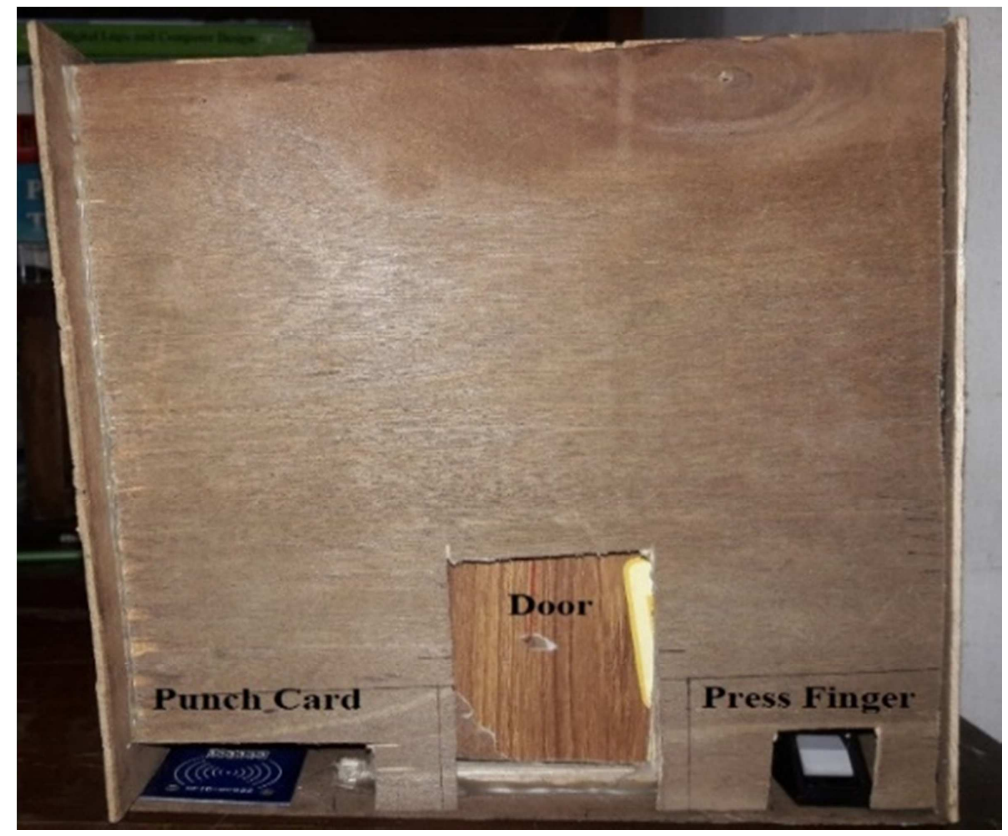

Figure 1. External view of the system. 


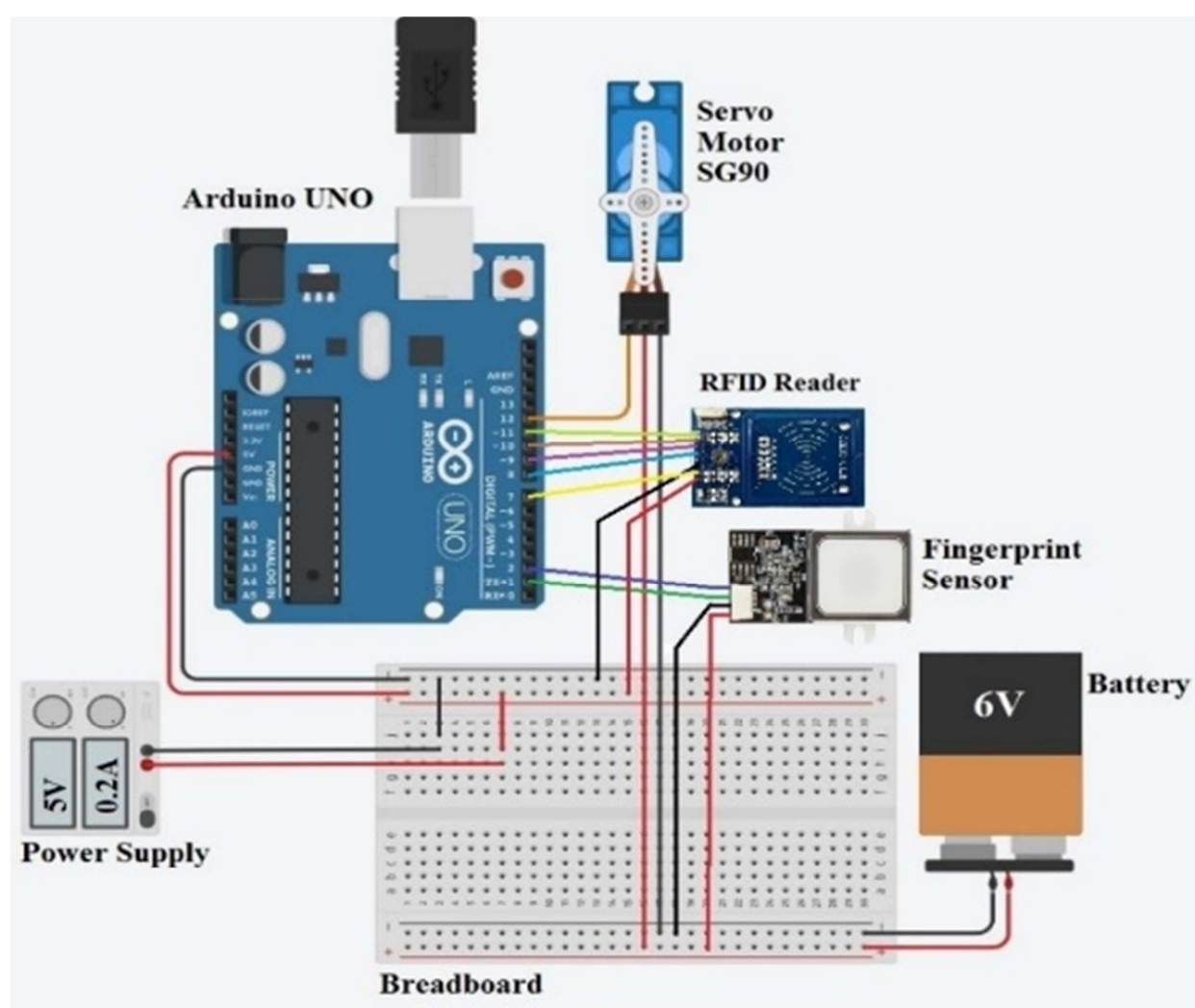

Figure 2. Circuit Diagram of Fingerprint unit.

\section{System Components}

The Security system can be broken down into four basic components: Arduino, servo motor, RFID unit, and fingerprint unit. Each component has its prominent use with subtle functionality.

\subsection{Arduino Board}

Arduino is an open-source venture for building computerized gadgets and intelligent items that can detect and control physical gadgets. The UNO version of it is utilized here as a miniaturized scale controller gadget for working the capacity of this proposed security system.
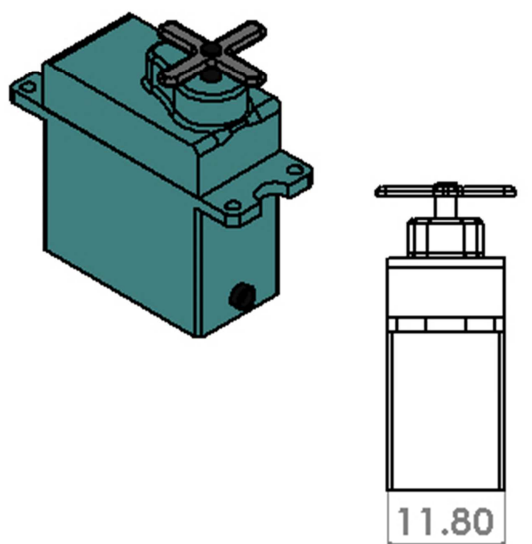

\subsection{Servo Motor}

A servo control is a standout amongst the most essential and generally utilized as a part of the control system. Servo instruments permit powerful gadgets to be controlled by signals from gadgets of much lower control [13]. The movement of door bar is controlled by the servo motor SG90. The power is provided to servomotor through an outer connector. All the gears of it are metal. The $4.8-7.2 \mathrm{~V}$ is considered as working voltage. Photographic view of servo motor SG90 with its distinctive parts measurement is appeared in following Figure 3.
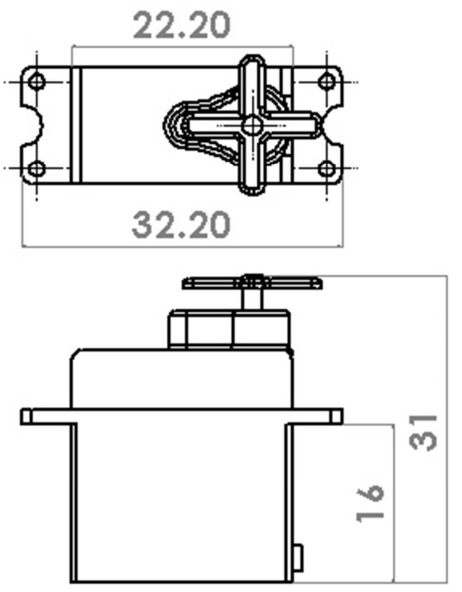

Figure 3. Servo motor $S G 90[8]$ 


\subsection{RFID Unit}

The RFID gadget fills an indistinguishable need from a standardized identification or an attractive strip on the back of a charge card or ATM card; it gives a one of a kind identifier to that protest. Furthermore, similarly as a scanner tag or attractive strip must be checked to get the data, the RFID gadget must be filtered to recover the recognizing data [14]. The examined data from RFID label go to RFID per user first. At that point, it is exchanged to microcontroller framework and changed over as database framework. This process of examining the data is used here to identify the validity of the person who is supposed to unlock the door. A stream chart of RFID task is appeared in following Figure 4.

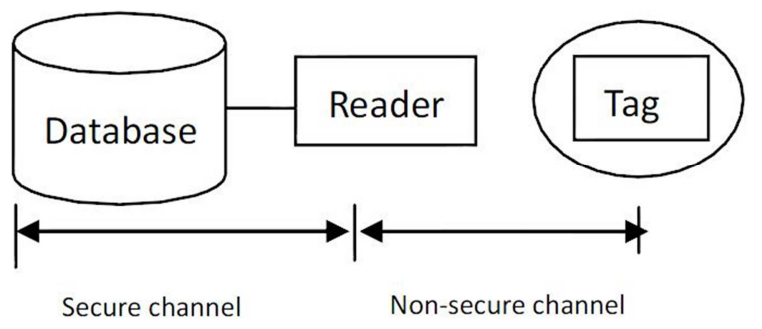

Figure 4. Flow diagram of RFID operation [15].

\subsection{Fingerprint Unit}

Fingerprint-based authentication is the most advanced and accepted biometrics technologies [16-19]. The fingerprint validation alludes to the robotized technique for checking a match between two human fingerprints. The processing of fingerprint has three essential functions: enrollment, searching, and verification. Among these functions, enrollment which catches fingerprint picture from the sensor assumes a critical part. A reason is that the way individuals put their fingerprints on a mirror to output can influence the outcome in the searching and checking process. This unit is utilized here to doubly secure the security system.

\section{Working Principle of the System}

The working principle of the system is divided into three sections. They are detailed below:

\subsection{RFID Card Punching and Operating}

RFID is a major and modest innovation that empowers wireless information transmission [20]. The RFID reader module is powered from the external power supply and Arduino is powered from the $5 \mathrm{~V}$ supply. For interfacing of RFID reader with an Arduino, five RFID wires are connected with five digital ports of Arduino. Both of the grounds pin of Arduino and RFID reader is connected. The RFID reader reads the RFID labels, a controller is utilized to acknowledge the information from the RFID reader and control the output of the security door lock and the RGB LED.

The RFID reader is set outwardly of the entryway and it is disconnected from the controller secretly so that nobody can break the RFID reader for avoiding the security. The controller of this task gets serial data from the RFID reader and controls the Door bolt and the LED.

\subsection{Fingerprint Installing and Sensing}

\subsubsection{Enrolling the Fingerprint}

A pattern of interleaved ridges and valleys are the main component of a fingerprint. They easily stream in parallel and once in a while end or bifurcate. The pattern of ridges and valleys can show a specific shape called minutiae at a local level [21]. There are a few kinds of minutiae as shown in Figure 5, yet for pragmatic reasons, just two sorts of details are considered: ridge ending and ridge bifurcation [6]. The terms of fingerprint structures and their definitions are depicted in Table 1.

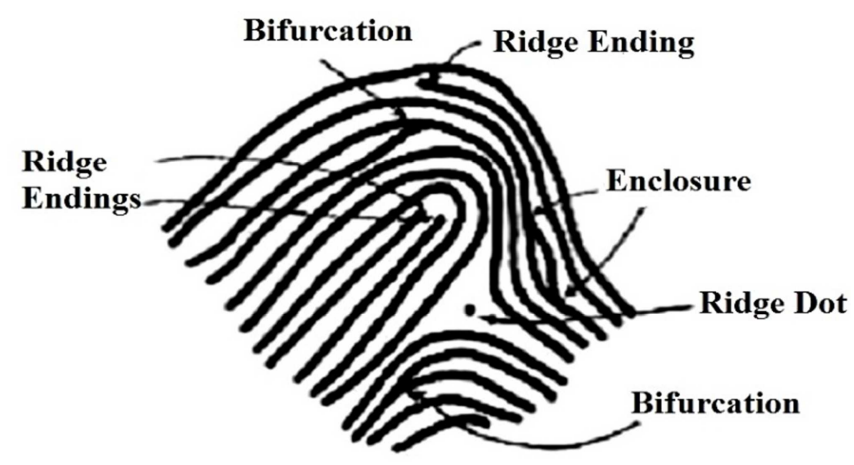

Figure 5. Different ridge features on fingerprint image [11].

There are fundamentally two prerequisites for utilizing the optical fingerprint sensor. Firstly, the fingerprints should be enrolled - that implies designating ID \#'s to each print so that they can be checked later. Once enlisted all prints, the sensor can easily be searched by asking which ID (assuming any) is at present being shot. This enrollment is done by utilizing the windows programming software or with the Arduino programming.

\subsubsection{Enrolling New User}

The most effortless approach to do this is to associate it specifically to the USB/Serial converter in the Arduino. To do this, a blank sketch is uploaded using Arduino Uno and the fingerprint sensor is directly connected to the USB/Serial. When the power supply is provided, the red LED blink to indicate the sensor is working.

\subsubsection{Wiring for Use with Arduino}

After testing the sensor, it can be used to verify a fingerprint. The fingerprint is attached with Arduino through the jumper wire. The Tx of Fingerprint sensor is connected to the digital $2(\mathrm{Rx})$ of Arduino Uno and both of their ground pins is connected. The RFID reader module is powered from the external power supply and Arduino is powered from the $5 \mathrm{~V}$ supply. So, the green and white wires are disconnected and the green wire is plugged into digital 2 and the white wire to digital 3. Interfacing of fingerprint sensor with Arduino is shown in following Figure 6. 
Table 1. Terms and Definition of Fingerprint Structures [22].

\begin{tabular}{lll}
\hline No & Term & Definition \\
\hline 01 & Termination & The location where a ridge come to an end \\
02 & Bifurcation & The location where a ridge divides into two separate ridges \\
03 & Binarization & A process to transform the image from 256 levels to two levels $(0,1)$ refers to (black and white) respectively \\
04 & Thinning & The process of reducing the width of each ridge to one pixel \\
05 & Termination Angle & Considered as angle between the direction of the ridge and the horizontal \\
06 & Bifurcation Angle & Which Considered as the angle between the direction of the valley ending between the bifurcations and the horizontal \\
07 & Matching Score & It is the measure of similarity between the input and template data \\
08 & False Non Matching Ratio & The system fail to detect a match between input and template in database \\
\hline
\end{tabular}

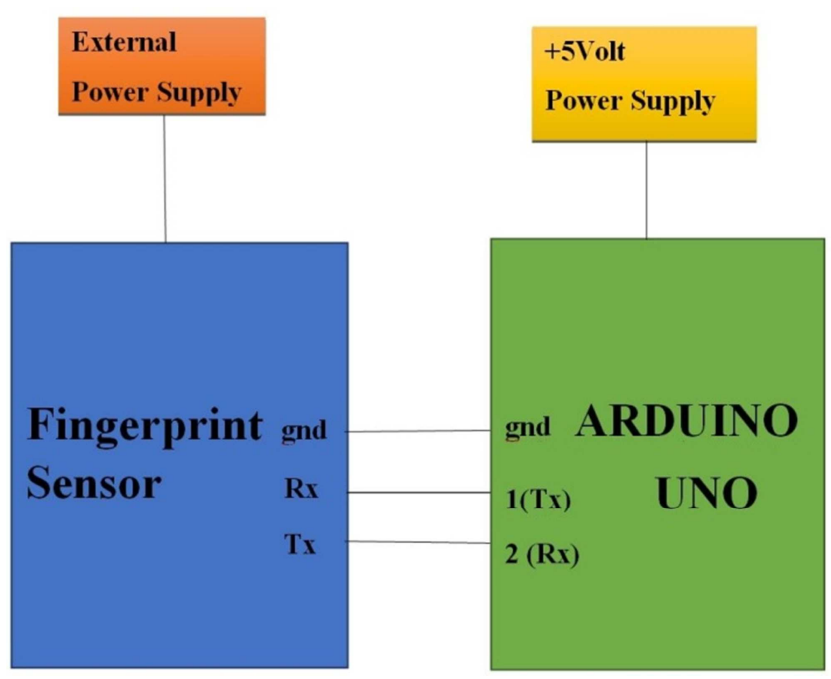

Figure 6. Interfacing of fingerprint sensor with Arduino.

\subsubsection{Sensing System of Fingerprint}

There are fundamentally two types of filtering techniques for this innovation. Either an optical or capacitance scanner is utilized to scan and make a photo of the finger. In spite of the fact that both the techniques create a similar sort of picture, the process of scanning picture is totally extraordinary. This checked picture is then contrasted with before existing fingerprints to get the right character. The examination is done by the processor and the correlation is made between the valleys and ridges.

The sensing of the fingerprint is done by the following several steps. Firstly, the image is taken with the assistance of information gadgets like camera, sensors, and so forth. It is done by the inward camera of the fingerprint sensor. Secondly, the normalization process of the image. This procedure incorporates dim scale transformation of the picture of the fingerprint. The third step includes filtering. The sensor from which the picture is taken might be old or pore with tidy. At old age, a man's fingerprint may not be clear by any stretch of the imagination, in light of the fact that the edges of his/her fingerprints move toward becoming into broken parts. Therefore, for better estimation, this fingerprints should be redrawn and filtered for getting surmised full edge print. The fourth process involves thinning.

In this process, the pictures are thinned for expelling clamors and make the ridges thinned. The fifth step is Ridge Orientation. The picture is first changed over into binary format. The bearing field of ridges is taken for getting the minutiae angle in the fingerprint.

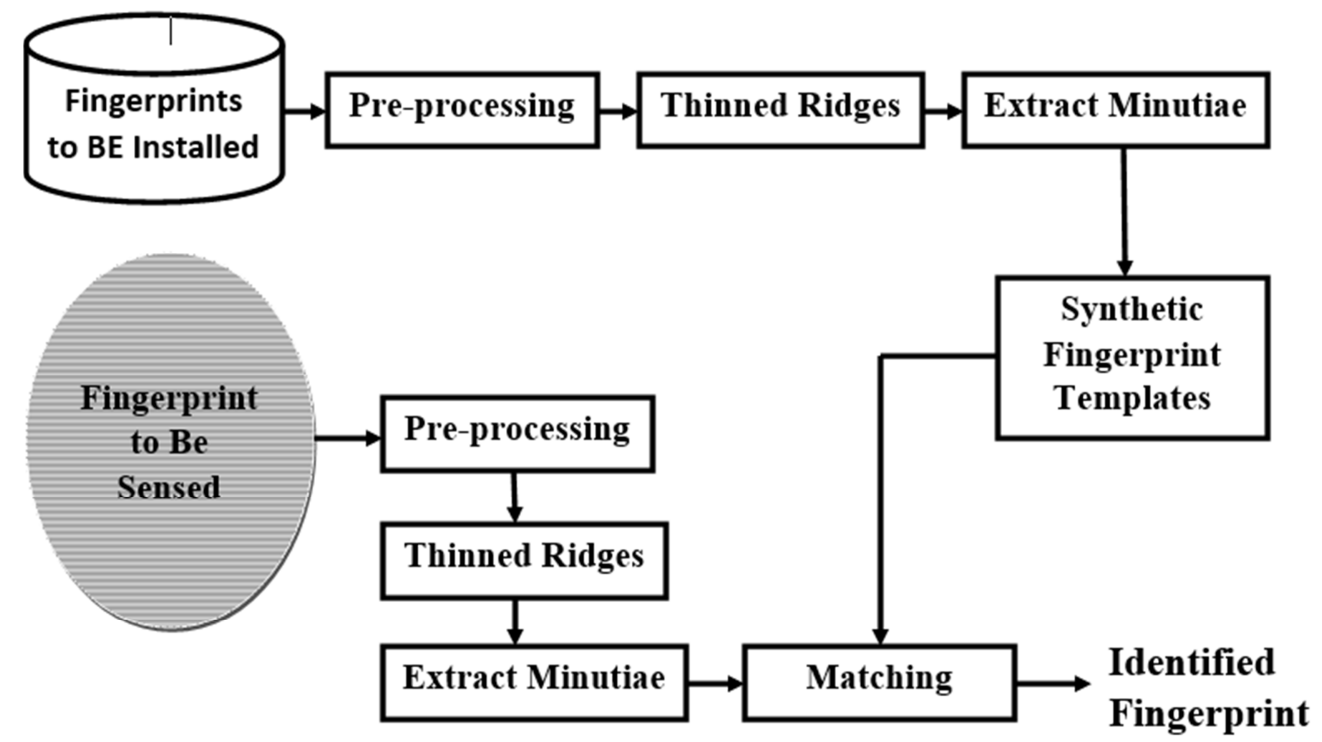

Figure 7. Fingerprint detecting process of fingerprint sensor [7]. 


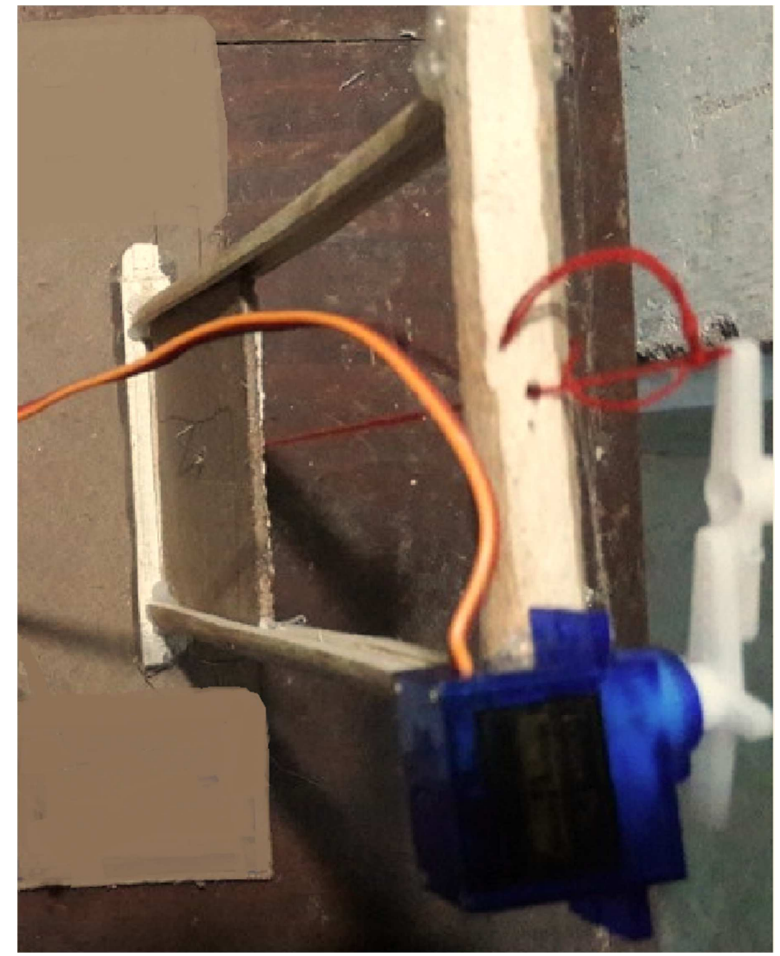

Figure 8. Door bar control by servo motor.

Joining of focuses on edges, which are made at the time of filtering and thinning give the directional field for ridges. This likewise discovers the minutiae points [21]. A flowchart of the activity of fingerprint detecting system in fingerprint sensor has appeared in Figure 7.

\subsection{Door Control by Servo Motor}

When both RFID tag and fingerprint is detected valid then servo motor operates to open the door. Servo motor rotates 90 degrees left to draw the door bar vertically and provide an access to open door condition. The door gets automatically close after few seconds. In that case, servo motor rotates reversed 90 degrees to right and the door moves down to close the entrance. Door controlling operation with servo motor SG90 is shown in following Figure 8.

\section{Construction of the System}

The system consists of both electrical and mechanical parts. Mechanical parts are related to the servo motor rotation and the mechanism of door bar control for closing the door and opening the door. The different mechanism can be possible to operate the door bar by the servo motor. Even using a hatch lock system is also beneficial in this case. Here, in this work, an emphasis is given mandatorily on electrical parts for a strong security system to barrier any invalid access to the door. Here, simply a small door bar is made and attached to the servo motor to operate mechanically. Small door bar is used as a demonstration of real door controlling system and the security system. The electrical part consists the connection of RFID unit, fingerprint sensor unit, servo motor controlling and Arduino board connection and their total circuit connection and providing a program to operate these electrical components by requisite means.

System based on both RFID \& Fingerprint. So if one system fails other system will back up the security. Both fingerprint \& RFID is needed to crack the security. RFID system consists of a RFID reader \& RFID tag. When RFID reader gets valid input then it will activate the fingerprint system. Fingerprint will command the lock when it will get valid fingerprint. Only the fingerprint \& RFID tag holder can unlock the system. A servo motor is also used for the operation of the movement of door bar to be open or close. All components are attached to Arduino Uno micro controlling system. The photographic view of internal arrangement of construction is shown in following Figure 9.

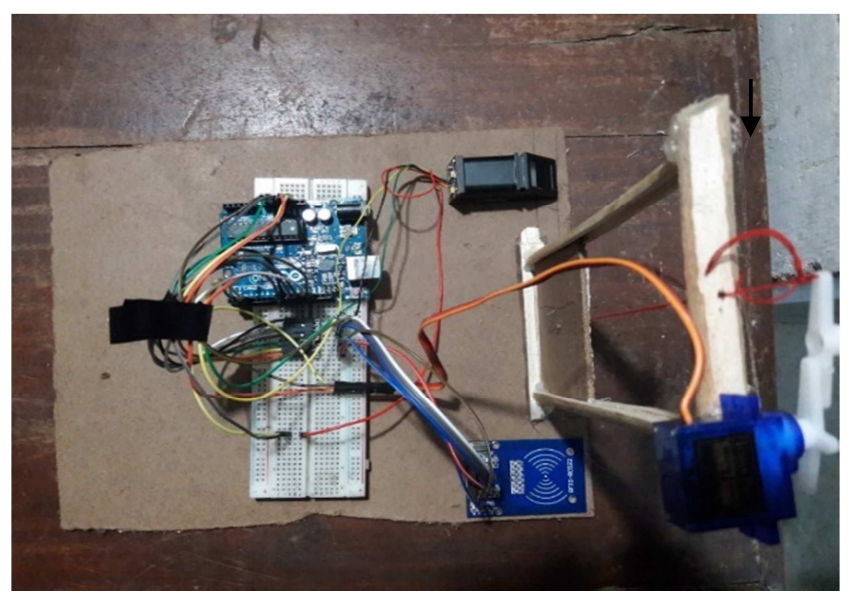

Figure 9. Internal arrangement of the system.

\section{Methodology and Performance Test}

\subsection{Methodology}

In order to check the performance of the system, a performance test has been done in several steps. The first step is to power the system. Secondly, the RFID tag is put close to RFID reader. If RFID reader finds a valid RFID tag then it will activate the fingerprint. In third step, finger is put on the fingerprint sensor. Fingerprint sensor will take an image and the finger and verify the fingerprint of the image with the fingerprints that was installed previously. A flow chart of the operation of the system is shown in following Figure 10. 


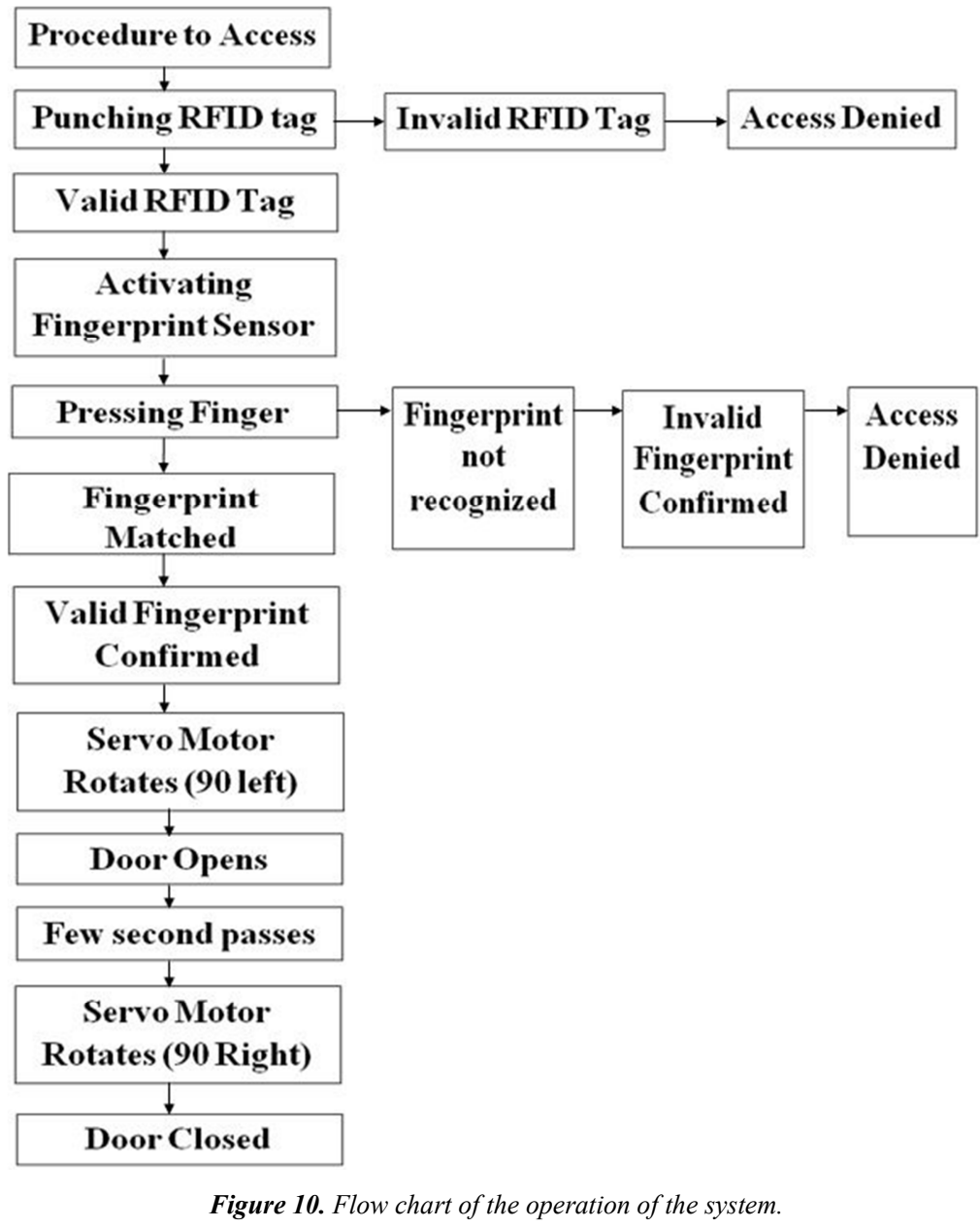

If the fingerprint of the image is matched with previous fingerprints then the microcontroller system Arduino will confirm it as valid finger and send a command to the servo motor to rotate 90 degrees left to open the door. The door will be automatically closed after a certain time. For that, after few seconds of opening the door, Arduino will command servo again to rotate 90 degrees right this time to close the door..

\subsection{Performance Test}

For measuring the performance test of the system, the methodology system was continued five times and the observation output result was shown in Table 2 as performance test data and result.

Table 2. Performance Test Data.

\begin{tabular}{lllll}
\hline $\begin{array}{l}\text { Observatio } \\
\text { ns no. }\end{array}$ & RFID Unit & Fingerprint Unit & Door Open & Door Close \\
\hline 01. & Success & Success & Success & Success \\
02. & Success & Success & Success & Success \\
03. & Failure & Success & Failure & Failure \\
04. & Success & Failure & Failure & Failure \\
05. & Success & Success & Success & Success \\
\hline
\end{tabular}

\section{Conclusion}

The world is being modernized day by days and it needs a technological backup with stronger protection and security of valuable secret code, hiding data, and items. This research work has the very purpose of providing robust security system with automatic sensing and operating action to access or decline. It is a developed safety security and impermeable to baffle this security system. Security is maintained with sequential operation of RFID and fingerprint sensor and without the missing of one, an abscess is denied. This security system is cheaper, flexible, less time consuming and also needs not to commit any code or password to access. Fingerprint scanning and sensing can also be used to protect computer files and data. It is very reliable security system and can provide the highest security and automatic operation for any kind of user.

\section{References}

[1] J. Baidya, T. Saha, R. Moyashir and R. Palit, "Design and implementation of a fingerprint based lock system for shared access," 2017 IEEE 7th Annual Computing and Communication Workshop and Conference (CCWC), Las Vegas, NV, 2017, pp. 1-6.

[2] U. Farooq, M. Hasan, M. Amar, A. Hanif, and M. U. Asad, "RFID based security and access control system", in International Journal of Engineering and Technology, Vol. 6, No. 4, August, 2014, pp. 309-314. 
[3] L. Wu, W. W. Y. Ng, D. S. Yeung and H. L. Ding, "A brief survey on current RFID applications," Proc. in International Conference on Machine Learning and Cybernetics, Baoding, 2009, pp. 2330-2335.

[4] Yu-Chih Huang, "Secure access control scheme of RFID system application" in Proc. Fifth International Conference on Information Assurance and Security, China, 2009.

[5] A. Juels, "RFID security and privacy: A Research survey, selected areas in communications", IEEE Journal on Publication, Volume: 24, Issue: 2, Feb. 2006, pp. 381-394.

[6] I. Yugashini, S. Vidhyasri, K. Gayathri Devi, "Design and implementation of automated door accessing system with face recognition", International Journal of Science and Modern Engineering (IJISME) ISSN: 2319-6386, Vol. 1, Issue-12, November 2013.

[7] O. Omidiora, O. A Fakolujo, O. T. Arulogun, D. O. Aborisade, "A prototype of a fingerprint based ignition systems in vehicles", in European Journal of Scientific Research, Vol. 62, Issue 2, October, 2011, pp. 164.

[8] A. Kawale, "Fingerprint based locking system" in International Journal of Scientific \& Engineering Research, Vol. 4, Issue 5, May-2013.

[9] R. P. Wildes. "Iris recognition: an emerging biometric technology", Proceedings of the IEEE, vol. 85, no. 9, September, 1997, pp. 1348-1363.

[10] X. L. Meng, Z. W. Song, and X. Y. Li, "RFID-Based security authentication system based on a novel face-recognition structure," in Proc. WASE International Conference on Information Engineering, 2010, pp. 97-100.

[11] D. L. Wu, W. W. Y. Ng, P. P. K. Chan, H. L. Ding, B. Z. Jing and D. S. Yeung, "Access control by RFID and face recognition based on neural network," Proc. in International Conference on Machine Learning and Cybernetics, Qingdao, 2010, pp. 675-680.

[12] L. H. Thai, H. N. Tam, "Fingerprint recognition using standardized fingerprint model" in International Journal of Computer Science Issues, Vol. 7, Issue 3, No 7, May 2010.
[13] T. Vanhuy, D. T. Minh, N. P. Kien, T. A. Vu, "Simple robotic hand in motion using arduino controlled servos", in International Journal of Science and Research (IJSR), Vol. 6, Issue 3, March, 2017, pp. 972-975.

[14] S. L. Ting, S. K. Kwok, A. H. C. Tsang and G. T. S. Ho, "The Study on using passive RFID tags for indoor positioning tagged objects", in International Journal of Engineering Business Management, Volume: 3, January 1, 2011, pp. 9-16.

[15] M. Wang, J. Pan, "Authentication test-based the RFID authentication protocol with security analysis", Sensors \& Transducers IFSA Publishing, S. L., Vol. 176, Issue 8, August 2014, pp. 196-202.

[16] N. K. Ratha, J. H. Connell, R. M. Bolle, "Secure data hyding in wavelet compressed fingerprint images", ACM Multimedia workshop Marina Del Rey CA USA, 2000.

[17] A. Nagar, K. Nandakumar, A. K. Jain, "A hybrid biometric crypto system for securing fingerprint mutiae templates", Pattern recognition Letters, Vol. 31, 2010, pp. 733-741.

[18] A. Farina, Z. M. Kovács-Vajna and A. Leone, "Fingerprint minutiae xtraction from skeletonized binary images," Journal of the pattern recognition society, Vol. 32, Issue 5, Bologna Italy 1999, pp. 877-889.

[19] A. K. Jain, S. Prabhakar, L. Hong and S. Pankanti, "Filterbank-based fingerprint matching," in IEEE Transactions on Image Processing, vol. 9, no. 5, pp. 846-859, May 2000.

[20] F. L. Podio, "Personal authentication through biometric technologies", in Proc. 2002 IEEE 4th International Workshop on Networked Appliances (Cat. No. 02EX525), Gaithersburg, MD, 2002, pp. 57-66.

[21] L. M. Mwaringa and T. Biketi. "Finger print based automotive security lock system.", 2016 Annual Conference on Sustainable Research and Innovation, 4 - 6 May 2016, pp. 295-298.

[22] M. M. H. Ali, V. H. Mahale, P. Yannawar and A. T. Gaikwad, "Overview of fingerprint recognition system," 2016 International Conference on Electrical, Electronics, and Optimization Techniques (ICEEOT), Chennai, 2016, pp. 1334-1338. 